\title{
Iatrogenic Damage to Periodontium by Restorative Treatment Procedures: An Overview
}

\author{
Syed Sirajuddin*, Kumuda M. Narasappa, Veenadharini Gundapaneni, Sachidananda Chungkham \\ and Ambica S. Walikar
}

Department of Periodontology, Rajarajeswari Dental College \& Hospital, Bangalore-560074. Karnataka, India

\begin{abstract}
The regenerative capability found in most other tissues is not possessed by teeth. Hence, enamel or dentin once lost as a result of caries, trauma, wear, and restorative materials must be replaced to restore form and function. Teeth require preparation to receive restorations, and these preparations must be based on fundamental principles from which basic criteria can be developed to help predict the success of restorative treatment.
\end{abstract}

Keywords: Iatrogenic effect, pulp, restorative materials, root caries, trauma.

\section{INTRODUCTION}

Periodontal tissues play an important role in proper esthetics, function, and comfort of the dentition. Healthy periodontium is required for all prosthetic and restorative therapies as a prerequisite for successful outcome. The interplay between periodontics and restorative dentistry is present at many fronts, including location of restorative margins, crown contours, and response of the gingival tissues to restorative preparations. The close relationship of iatrogenic factors with periodontal breakdown was originally recognized by Black 1912 [1]. The relationship between dental restorations and periodontal health has been thoroughly investigated for many years. Many studies have focused their attention on different aspects of the periodontal- restorative interaction, such as "position of the restoration with respect to the gingival margin, presence of overhangs, presence of marginal leakage, roughness of the surfaces, and the type of restorative material" [2].

The most reliable mechanism by which dental restorations may affect marginal health is the increase of plaque accumulation; however, modifications of the composition of the subgingival microbiota have also been described in the presence of overhanging metal restorations with an increase in putative periodonto pathogenic micro flora [3]. Crosssectional data on the microbiological changes occurring in the subgingival flora after the placement of well subgingival restorations performed with different materials used in dentistry were reported by van Dijken et al. [4], whereas longitudinal observations are still lacking.

The marginal periodontium is a location the fields of restorative dentistry and periodontics overlap. Conversely, a close attention should be paid to the response of the periodontium to the irritants arising from careless techniques, which can initiate or add to existing gingival inflammation. In turn, loss of periodontal support and subsequent tooth loss

*Address correspondence to this author at the Department of Periodontology, Rajarajeswari Dental College and Hospital, Mysore road. Bangalore560074, Karnataka, India; Tel: 09845904048;

E-mail: sirrushah@yahoo.co.in can result if the condition is not recognized and treated in its early stages. Dental restorations or appliances are frequently associated with the development of gingival inflammation, especially when they are located subgingivally. This may apply to subgingivally, placed on lays, crowns, fillings, and orthodontic bands. Restorations may impinge on the biologic width by being placed deep in the sulcus or within the junctional epithelium. This may promote inflammation and loss of clinical attachment with apical migration of the junctional epithelium and reestablishment of the attachment apparatus at a more apical level. Diseased pulps and missing tooth structure are replaced routinely with inert materials, but no material can substitute for a lost periodontal ligament.

Data available on the effects of composite resin restorations on gingival health are still controversial. Larato [5] reported that class $\mathrm{V}$ composite resin restorations adjacent to subgingival region leads to gingival inflammation. Hammer \& Hotz reported more frequent inflammatory processes of the gingiva in the presence of composite resin restorations, than those with the placement of metal restorations [6]. Similarly, Willershausen et al. [7] reported increased gingival bleeding and an increased probing depth with the use of resin-based restorations, as compared with other restorative materials.

Blank et al. [8] observed that the health of the gingiva is not affected by correctly finished and contoured composite resin restorations, and Van Dijken et al. [9] reported that gingival inflammation was not significant with 1- year old composite resin restorations that are given subgingivally. However van Dijken et al. [9] reported significant increased gingival inflammation with 3-4 year-old composite resin restorations. This observation is based on principle that the surface deterioration with a subsequent increase in plaque accumulation occurs after in vivo wear in composite resin restorations. This observation can explain the relationship between subgingival composite resin restorations and gingival health.

Antibacterial activity has been reported with amalgam, and this is due to the presence of mercury, copper, and zinc. 
Similarly, fluoride, which continuously seeps from the surface of the glass ionomer cement, interferes with the early adherence of bacteria to the restoration surface [10]. The growth and metabolism of the bacteria are also suppressed by fluoride.

Van Dijken and Sjostrom found "significant alterations in the amount of gingival crevicular fluid (GCF) around sound tooth surfaces and 1-year-old composite resin restorations, from which he concluded that although not macroscopically evident, subclinical gingival inflammation may be produced by composite resin restorations" [10].

\section{MARGINS OF RESTORATIONS}

Deficient dental restorations or prostheses are the contributing factors to gingival inflammation and periodontal destruction. Inadequate dental procedures that contribute to the deterioration of the periodontal tissues are referred to as iatrogenic factors.

Features of dental restorations and removable partial dentures that are significant to the maintenance of periodontal health include,

(1) The placement of the gingival margin for the restoration,

(2) The space between the margin of the restoration and the unprepared tooth,

(3) The contour of restorations,

(4) The occlusion,

(5) Materials used in the restoration,

(6) The restorative procedure itself, and

(7) The design of the removable partial denture.

The information of biologic width should be applied when positioning the restorative margins, particularly in the esthetic zone where the main treatment goal is to cover the junction of the margin with the tooth. on,

The placement of the restoration margin depends greatly

1. Esthetics.

2. Need for additional retention of the restoration.

3. Degree of personal oral hygiene.

4. Susceptibility of the individual to root caries.

5. Susceptibility of the marginal gingiva to irritants.

6. Morphological characteristics of the marginal gingival.

7. Degree of gingival recession.

8. Severe cervical abrasion.

9. Overhanging margins of dental restorations.

Over hanging margins of dental restorations add to the severity of periodontal disease by,

1. Altering the ecologic balance of the gingival sulcus to an area that favors the growth of disease-associated organisms (predominantly gram-negative anaerobic species) at the cost of the health-associated organisms (predominantly gram-positive facultative species) [11].
2. Preventing the patient's access to remove accumulated plaque (Fig. 1).

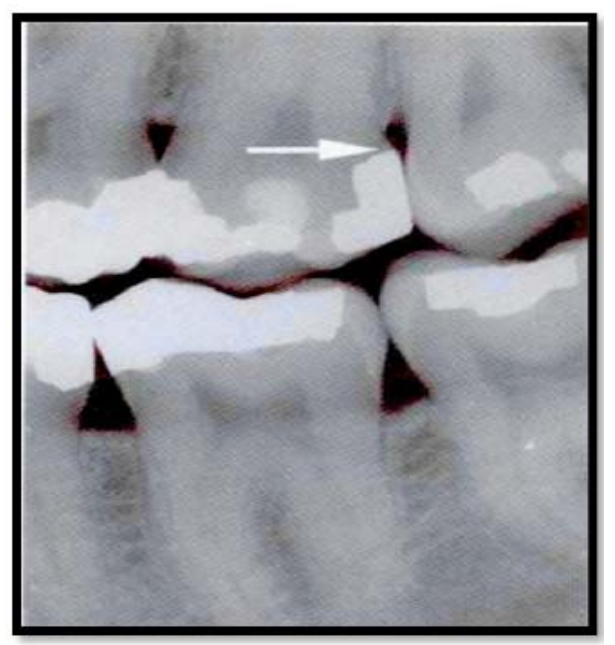

Fig. (1). Radiograph of amalgam overhanging on the distal surface of maxillary second molar that is a contributing source of plaque retention and gingival inflammation.

The frequency of overhanging margins of proximal restorations varies from $16.5 \%$ to $75 \%$ in different studies [12]. An extremely important statistical relationship has been reported between marginal defects and reduced bone height [13]. Removal ofoverhangs (Fig. 2) allows more effective plaque control, resulting in decreased gingival inflammation and a slight increase in radiographic alveolar bone support [14].

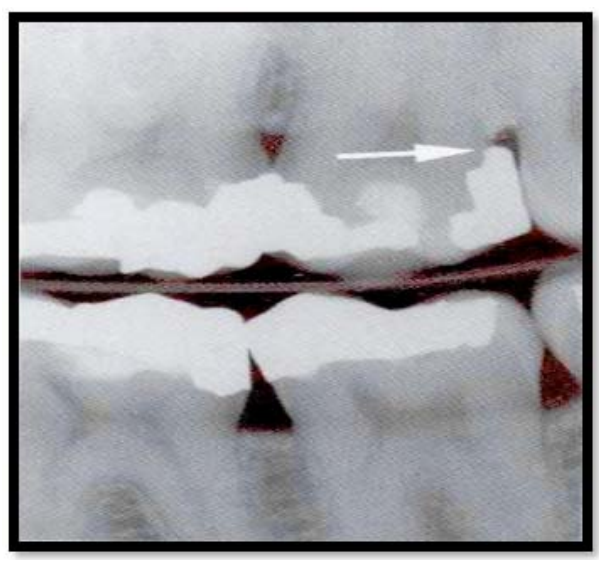

Fig. (2). Radiograph of the same patient after the amalgam has been removed.

Adjacent periodontal tissues play a role in the placement of gingival margins for a restoration [15].

Various studies have presented a positive correlation between marginslocated apical to the gingivalmargin and the presence of gingival inflammation [16]. Subgingival margins lead to increased plaque accumulation, more severe gingivitis, and deeper pockets.

Even high-quality restorations, if placed subgingivally, will increase plaque accumulation, gingival inflammationand the rate of gingival fluid flow [17]. 


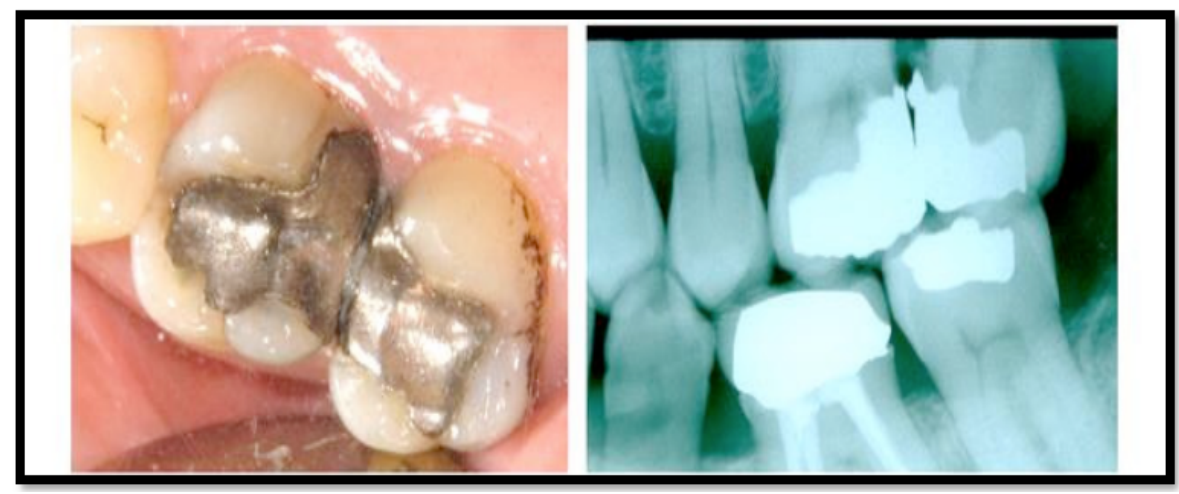

Fig. (3). Overhanging restoration.

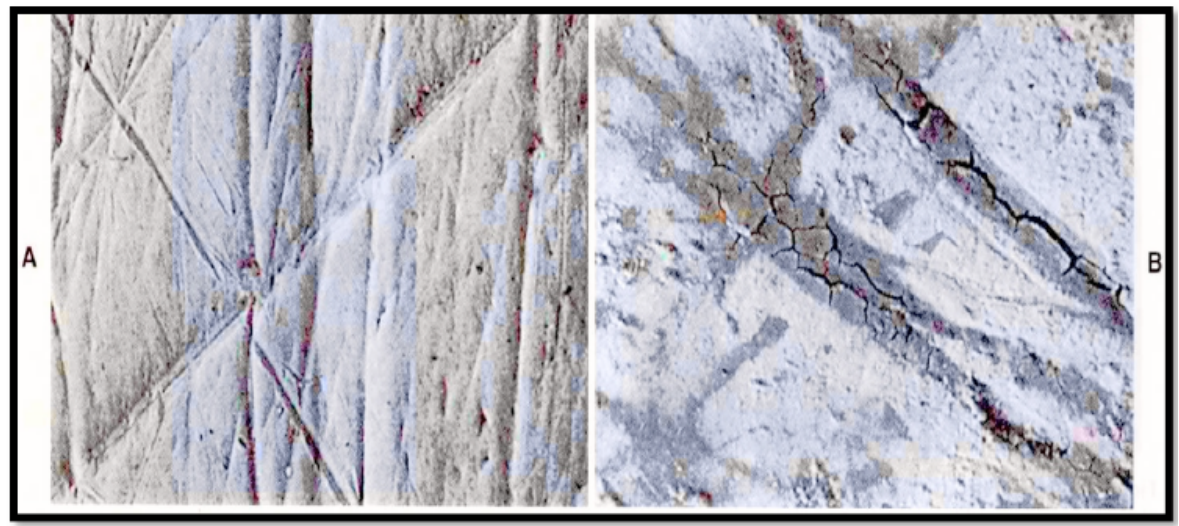

Fig. (4). A Polished gold alloy crown demonstrates surface scratch. B.Gold alloy crown that had been in the mouth for several years has scratches filled with deposits. (From Silness J: Dental Clin North Am 24: 317, 1980. 2).

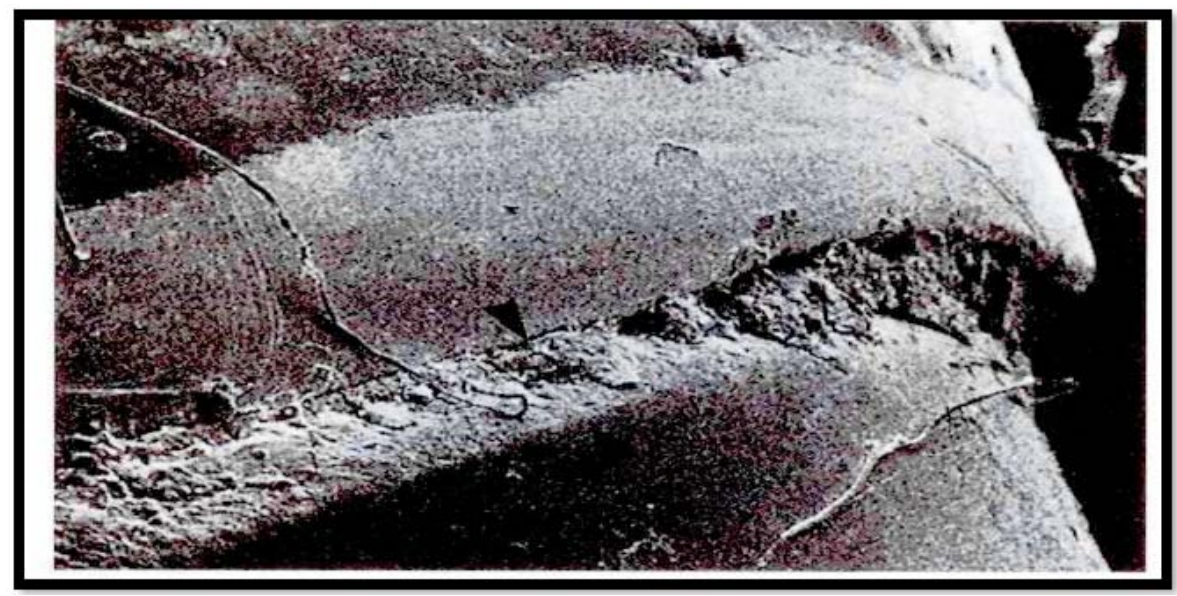

Fig. (5). After cementation, luting material prevents approximation of the crown margin and the finishing line, leaving part of the prepared tooth uncovered (area between arrowheads) (From Silness J: Dent Clin North Am 24: 317, 1980).

Margins placed at the level of the gingival crest cause less severe gingival inflammation compared to subgingivally placed margins, where as supragingival margins are associated with a degree of periodontal health similar to that seen with non-restored interproximal surfaces [18].

Roughness in the subgingival (Fig. 3) area is said to be a major contributing factor to plaque accumulation and subsequent gingival inflammation [19]. The subgingival zone is composed of the margin of the restoration, the luting material, and the prepared as well as the unprepared tooth surface.
Marginal roughness is because of following sources:

1) Grooves and scratches present in the surface of carefully polished acrylic resin, porcelain, or gold restorations (Fig. 4).

2) Separation of the restoration margin and luting material from the cervical finish line, thereby exposing the rough surface of the prepared tooth (Fig. 5).

3) Inadequate marginal fit of the restoration. Subgingival margins typically have a gap of 20 to $40 \mu \mathrm{m}$ between the 
margin of the restoration and the un-prepared tooth. Colonization of this gap by bacterial plaque undoubtedly contributes to the detrimental effect of margins placed in a subgingival environment.

4) Dissolution and fragmentation of the luting material between the preparation and the restoration, leaving a space (Fig. 6).

Patients existing sulcus depth should be considered and used as a guideline when restorative margins are placed.

1. If the sulcus probes $1.5 \mathrm{~mm}$ or less, the margin of the restoration should be placed $0.5 \mathrm{~mm}$ below the crest of the gingival tissue. This is particularly significant on the facial aspect and prevents biologic width destruction in a patient who is at high risk.

2. If the sulcus probes more than $1.5 \mathrm{~mm}$, the margin should be placed below the crest of the gingival tissue at one half the depth of the sulcus.

3 . If the sulcus is greater than $2 \mathrm{~mm}$, then it has to be assessed whether to lengthen the teeth by gingivec to my to create a sulcus depth of $1.5 \mathrm{~mm}$. Then follow rule 1 . The rationale for rule 3 is that deep margin placement is more demanding and the stability of the free gingival margin is less predictable when a deep sulcus is present.

The major cause of plaque buildup and the resultant inflammatory response is due to roughness of the restoration in the subgingival area [20]. The subgingival zone is made up of the crown and the margin of the restoration, the luting material, and the prepared tooth surface. Various types of roughness have been described like:

- Stripes and scratches in the surface of properly polished acrylic resin, porcelain, or gold restorations.

- Separation of the cervical crown margin and the cervical margins of the finishing line by the luting material, exposing the rough surface of the prepared tooth.

- Dissolution and disintegration of the luting material, causing crater formation between the preparation and the restoration. And the inadequate margin fit of the restoration.

\section{CAVITY PREPARATION}

Care should be taken not to damage the gingival tissues during cavity preparation. Slight abrasions heal rapidly, but it can be avoided if possible, as such abrasions cause recession, thus depleting the entire zone of attached gingiva and recession. Even biologic width should be taken in to consideration when the margins have to be placed within the gingival crevice as it's the most susceptible of all the supporting structures to periodontal disease. To avoid this, rubber dam can be used or a thin blunted instrument to retract the free gingival margin or by using a retraction cord (ideally 2-0). Even intra crevicular margins can be placed less traumatically by the use of hand cutting instrument such as the margin trimmer. Retraction cord - prevents crevicular bleeding Prevents pooling of crevicular fluid during impression making.

\section{APPLICATION OF THE RUBBER DAM}

During routine operative procedures, therubber dam is exceptionally useful in guarding the surrounding gingival tissue. It protects thegingiva against abrasion and keeps the area free from contamination by saliva or debris, thus ensuring well placed restorations. It also retracts the free gingival margin which helps in placing the margins of the restoration intracrevicularly, to make good impressions, finishing the gingival margins of the restoration and once the restorations have been cemented, to remove excess cement and loose debris. During crown preparation though the rubber dam cannot be placed as it interferes with adequate intracrevicular margin extension in such cases, there are chances of excessive gingival abrasion with stones or burs. Such chances are more where the zone of attached gingiva is insufficient or where the surrounding gingival tissues are thin and delicate. Rubber dam clamps if forced subgingivally causes stripping of the junctional epithelium and gingival connective tissue attachment and it should not be placed for longer duration of time as it can cause ischemia which can lead to tissue sloughing and subsequent recession can result.

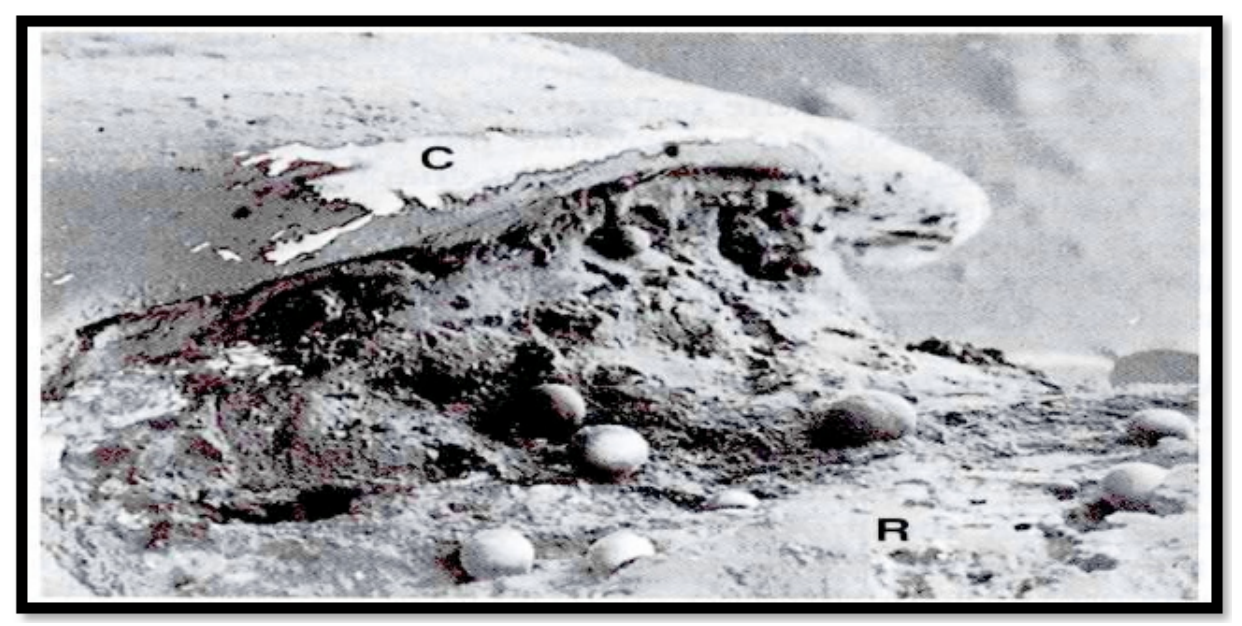

Fig. (6). Craters have formed after dissolution and disintegration of the luting material. Spherical bodies are not identified. C, Crown; R, root. (From Silness J: Dent Clin North Am 24: 31 7, 1980). 


\section{PLACING THE MATRIX}

After cavity preparation, a properly designed and contoured matrix should be placed so that it does not injure the biologic width and yet can be adapted accurately to the margins. In case of class II restorations, additional placements of interdental wedges are required for a well contoured restoration but it should be placed with care. Matrix should be rigid and well- contoured to reproduce proper form and to prevent intracrevicular overhangs.

Improperly Contoured Interdental Restorations Include:-

- insufficient or absent interdental contacts

- interdental under contour or over contour at the gingival third

- gingival over hangs

All these factors contribute to inter dental food impaction and exaggerated accumulation and retention of microbial plaque, which could result in caries and/ or periodontal break down. In judicious separation of anterior teeth for class III restoration can also cause injury to the periodontal ligament. Separation should be minimal and should not exceed the width of the periodontal ligament and any separating device should be removed as soon as possible.

\section{HYPERSENSITIVITY TO DENTAL MATERIALS}

Inflammatory gingival responses have been reported related to the use of nonprecious alloys in dental restorations [21]. Typically, the responses have occurred to alloys containing nickel, although the frequency of these occurrences is controversial [22]. Hypersensitivity responses to precious alloys are extremely rare, and these alloys provide an easy solution to the problems encountered with the nonprecious alloys.

More significantly, tissues respond more to the differences in surface roughness of the material than to the composition of the material [23]. The rougher the surface of the restoration subgingivally, the greater are the plaque accumulation and gingival inflammation.

In clinical research, porcelain highly polished gold, and highly polished resin all show similar plaque accumulation. Regardless of the restorative material selected, a smooth surface is essential on all materials subgingivally.

\section{PROVISIONAL RESTORATIONS}

Three critical areas must be effectively managed to produce a favorable biologic response to provisional restorations [24]. The marginal fit, crown contour, and surface finish of the interim restorations must be appropriate to maintain the health and position of the gingival tissues during the interval until the final restorations are delivered. Temporary restorations that are improperly adapted at the margins, that are over or under contoured, and that have rough or porous surfaces can result in inflammation, over growth, or recession of gingival tissues. The outcome can be unpredictable; and unfavorable changes in the tissue structures can compromise the success of the final restoration.

\section{MARGINAL FIT}

Marginal fit has clearly been implicated in producing an inflammatory response in the periodontium. It has been shown that the level of gingival inflammation can increase corresponding with the level of marginal opening [25]. Margins that are significantly open (several tenths of a millimeter are capable of harboring large numbers of bacteria and may be responsible for the inflammatory response seen. However, the quality of marginal finish and the margin location relative to the attachment are much more critical to the periodontium than the difference between a $20-\mu \mathrm{m}$ fit and a $100-\mu \mathrm{m}$ fit [26].

\section{CROWN CONTOUR}

Restoration contour has been described as extremely important to the preservation of periodontal health [27]. Proper contour provides access for hygiene, has the features to create the desired gingival form, and has an agreeable visual tooth contour in aesthetic areas.

Evidence from human and animal studies clearly demonstrate an association between over contouring and gingival inflammation, whereas under contouring does not produce any adverse periodontal effect [28]. The most common cause of over contoured restorations is insufficient tooth preparation by the dentist, which forces the technician to produce a bulky restoration to provide room for the restorative material. In areas of the mouth where aesthetic considerations are not critical, a flatter contour is always acceptable.

\section{SUBGINGIVAL DEBRIS}

An adverse periodontal response can be created if debris is left below the tissues during restorative procedures. The source can be retraction cord, impression material, provisional material, or either temporary or permanent cement [29]. The diagnosis of debris as the cause of gingival inflammation can be confirmed by examining the sulcus surrounding the restoration with an explorer, removing any foreign bodies, and then monitoring the tissue response. It may be necessary to provide tissue anesthesia for patient comfort during the procedure.

\section{CONCLUSION}

Periodontal health and dental restorations are very closely related. Periodontal health is essential for correct functioning of all restorations while the functional stimulation due to dental restorations is necessary for periodontal protection. Coronal obturations with incorrect occlusal modeling, oversized proximally or on the vestibular/oral surfaces of teeth, along with fillings, deficient inter proximal contact, negatively impact the healthy periodontium and, moreover, establish an added source of irritation for the periodontium already affected by disease.

The periodontium must remain healthy for restorations to last long term, so that the teeth are maintained. For the periodontium to remain healthy, restorations must be suitably managed in critical areas so that they are in harmony with their adjacent periodontal tissues. To retain or improve the patient's aesthetic appearance, the tooth / tissue interface 
must possess a healthy natural appearance, with gingival tissues surrounding the restored teeth in an appropriate manner.

\section{CONFLICT OF INTEREST}

The authors confirm that this article content has no conflict of interest.

\section{ACKNOWLEDGEMENTS}

Declared none.

\section{REFERENCES}

[1] Black A. Preventive treatment of periodontal diseases. NW Dental J 1912; 10: 60-73.

[2] Waerhaug J. Effect of rough surfaces upon gingival tissue. J Dent Res 1956; 35: 323-5.

[3] Lang NP, Kiel RA, Anderhalden K. Clinical and microbiological effects of subgingival restorations with overhanging or clinically perfect margins. J Clin Periodontol 1983; 10: 563-78.

[4] van Dijken JW, Sjöström S, Wing K. The effect of different types of composite resin fillings on marginal gingiva. J Clin Periodontol 1987; 14: 185-9.

[5] Larato DC. Influence of a composite resin restoration on the gingiva. J Prosthet Dent 1972; 28: 402-4

[6] Hammer B, Hotz P. Nachkontrolle von 1 bis 5 jahrigen amalgamkomposit- und gold full ungen. Schweiz Monatsschr Zahnheilkd 1979; 89: 301-14

[7] Willershausen B, Kottgen C, Ernst CP, The influence of restorative materials on marginal gingival. Eur J Med R 2001; 6(10): 433-9.

[8] Blank LW, Caffesse RG, Charbeneau GT. The gingival response to well-finished composite resin restorations. J Prosthet Dent 1979; 42: 626-32.

[9] Van Dijken JWV, Sjöström S. Development of gingivitis around aged restorations of resin-modified glass ionomer cement, polyacid-modified resin composite (compomer) and resin composite. Clin Oral Invest 1998; 2: 180-3.

[10] Van Dijken J, Persson S, Sjöström S. Presence of Streptococcus Mutans and lactobacilli in saliva and on enamel, glass ionomer cement, and composite resin surfaces. Scand J Dent Res 1991; 99: $13-9$.
[11] Icon A. Amalgam restorations and periodontal disease. Br Dent J 1976; 140: 377.

[12] Jeffcoat M, Howell T. Alveolar bone destruction due to overhanging amalgam in periodontal disease. J Periodontol 1980; 51: 599.

[13] Bjorn Al, Bjorn II, Grcovic B. Marginal fit of restorations and its relation to periodontal bone level. Wont Rev 1969; 20: 311 .

[14] Gorzo I, Newman H, Strahan J. Amalgam restoration, plaque removal and periodontal health. J Clin Periodontal 1979; 6: 98.

[15] Pack A, Coxhead L, McDonald B. The prevalence of overhanging margins in posterior amalgam restorations and periodontal consequences, J Clin Periodontol 1990; 17: 145.

[16] Karlsen K. Gingival reactions to dental restorations. Acta Odontol Scand 1970; 28: 895.

[17] Bergman B, Hugoson A, Olsson C. Periodontal and prosthetic conditions in patients treated with removable partial dentures and artificial crowns. Acta Odontol Scand 1971; 29: 621.

[18] Flores-de -Jacoby I, Zafiropoulos G, Ciancio S. The effect of crown margin location on plaque and periodontal health. Int J Periodont Restor Dent 1989; 9: 197.

[19] Huttner G. Follow-up study of crowns and abutments with regard to the crown edge and the marginal periodontium. Dtschr Zahnarztl Z 1971; 26: 724 .

[20] Silness J. Fixed prosthodontics and periodontal health. Dent Clin North Am 1980; 24: 317-29.

[21] Pierce LH, Goodkind RJ. A status report of possible risks in base metal alloys and their components. J Prosthet Dent 1989; 62: 234.

[22] Pelton L. Nickel sensibility in the general population. Contact Derm 1979; 5: 2 -7.

[23] Swartz ML, Phillips RW. Comparison of bacterial accumulations on rough and smooth surfaces. J Periodontol 1957; 28: 304.

[24] Yuodelis RA, Faucher R. Provisional restorations: an integrated approach to periodontics and restorative dentistry. Dent Clin North Am 1980; 24: 285 .

[25] Felton DA, Kanoy Be, Bayne SC, et al. Effect of in vivo crown margin discrepancies on periodontal health. J Prosthet Dent 1991; 65: 357.

[26] Marcum JS. The effect of crown margin depth upon gingival tissue J Prosthet Dent 1967; 17: 479.

[27] Hochman N, Yaffe A, Ehrlich J. Crown contour variation in gingival health. Compend Contin Educ Dent 1983; 4: 360.

[28] Parkinson CF. Excessive crown contours facilitate endemic plaque niches. J Prosthet Dent 1976; 35: 424.

[29] Price C, Whitehead FJH. Impression material as foreign bodies. $\mathrm{Br}$ Dent J 1972; 133: 9.

Received: December 22, 2014

Revised: March 04, 2015

Accepted: March 10, 2015

(C) Sirajuddin et al.; Licensee Bentham Open.

This is an open access article licensed under the terms of the Creative Commons Attribution Non-Commercial License (http://creativecommons.org/licenses/by-nc/3.0/) which permits unrestricted, non-commercial use, distribution and reproduction in any medium, provided the work is properly cited. 